\title{
Semiotic Interpretation on the Female Image of "Internet Celebrities"
}

\author{
Xiaoyu Jia \\ School of Literature and Journalism, Sichuan University, Chengdu, Sichuan Province, China
}

Keywords: Internet Celebrities, Female Image, Semiotics.

\begin{abstract}
With the advent and development of the Internet era, the phenomenon of "Internet celebrities" came into being. From grass root idols in the past to beautiful models nowadays, Internet culture has undergone continuous innovations. Now the word of "Internet celebrity" becomes a narrow definition which refer to a kind of women. This paper interprets this phenomenon from the perspective of semiotics, trying to understand the formation and dissemination processes of this female image, and analyze the motivation behind the symbol consumption.
\end{abstract}

\section{Introduction}

In the broad sense, "Internet celebrity" refers to people who become famous through the Internet. In the early development stage of Internet era, individualized, grass root users could attract public's attention quickly. With the continuous development of network culture, net users generally lose interest in creating idols. "Internet celebrities" are no longer the products of netizens' collective consciousness; they show a trend of fine differentiation. There are different types of Internet celebrities, such as well-known punsters and public intellectuals. In recent years, the female image of "Internet celebrity" has changed from ugliness appreciation to beauty appreciation. In 2015, Sina Weibo organized a survey on citizens' impression on "Internet celebrity"; three words with highest correlation with female are "beauty", "fashion" and "top selling products". In the new network context, the narrow sense of "Internet celebrity" refers to female e-commerce sellers who stimulate consumption through showing their daily life and clothing style on the Internet. "Internet celebrities" have become a strong economic driving force through their outstanding appearance and all kinds of social entertainment news. The year of 2015 is also known as "the first year of Internet celebrities".

From the perspective of semiotics, symbols are perceptions which are accepted through their meanings; individual display is narrative symbolic texts. Thus, every female image of "Internet celebrity" can be seen as a symbol text. Symbol coders convey meanings to Internet users, or decoders, through multi-media fusion display. In the era of symbolic consumption, public's attention make "Internet celebrities" become the typical image of contemporary women. Male audiences are obsessed with these women; female audiences follow these symbols blindly. It reflects the "deep typification" of women image in the social and cultural context. From the perspective of semiotics, this paper deconstructs this female image and helps readers to understand this unique network phenomenon.

\section{The Symbol Type of "Internet Celebrity"}

The "Internet celebrity" group has extremely obvious features. Most of them are young women like 20 years old; they have delicate appearances, follow Korean photography and clothing styles, and speak like little girls. Most of these "Internet celebrities" sell women's dress through Taobao. For them, showing their own dressing styles is a way of marketing. In social media, they usually combine pictures and words to form a multi media symbol text, in which different symbolic attributes jointly construct an all-round female image.

\subsection{The symbolic attribute of "Internet celebrity" in light of Peirce's Trichotomy Theory.}

Charles Sanders Peirce is the most important founder of semiotics; he put forward many 
trichotomy theories about symbols. In Peirce's opinion, according to the relationship between symbols and objects, symbols could be divided into three groups: icon, index and symbol. According to their attributes, they could also be divided into rational symbols (icon and index) and arbitrary symbols (symbol). The Trichotomy Theory can explain all kinds of symbolic phenomena. For example, when constructing the image of "Internet celebrity", a large number of different symbols are needed to form a whole symbolic text.

Indexes. As a kind of rational symbol, index represents some relationships between symbol and object, especially the cause and effect, the adjacency relation, and the relationship of the whole to the parts. Index and the object are co-reference. The function of index is to draw interpreters' attention to the object. Peirce said, "An index is physically connected to the object; index and object constitute an organic pair. Interpreters do not need to relate to this connection, but they must notice this connection after it is formed." [1]

In the platform of social network, index has the function of identity confirmation. The word of "Internet celebrity" is an index, which clearly indicates that these people are "celebrities" with high attention degree. The word of "Internet celebrity" conveys information to interpreters through the attributes of an index. Secondly, the identities of "Internet celebrities" are also indexes. Weibo and other social networking platforms are the birthplace of most Internet celebrities. These Internet celebrities usually identified themselves as "models" in self introduction. The authority of Weibo acknowledges their identities through real name authentication, which is a typical index. After authentication, a golden $\mathrm{V}$ symbol will be put beside the user's head portrait. As time passes, people tend to link "Internet celebrity" with the image of "beautiful" female models. The image of "Internet celebrity" is then established.

At the same time, index has another extremely important function: establishing orders. Indexes does not only indicate where the object is, but also indicate its order. It is the unique function of index. The large number of indexes in social platform not only indicate the locations of users, but also help them to establish identity orders in the platform. For instance, the search service of many social platforms indicates different users through their attributes. Women's channels of "beauty makeup" and "beautiful models" have become the exclusive territory of "Internet celebrities". In other words, these names also become the indexes of "Internet celebrities". This series of indexes clearly indicate the position and field of "Internet celebrities" in the world of Internet, and indicate the feminine characteristics of "Internet celebrities": "beautiful" and pay attention to appearances. The image of female is then stereotyped.

Icons. Icons indicate objects depend on "iconicity". That is, symbols can convey meanings because they have semblance with objects. As a virtual world, the Internet is full of icons which are similar to real world objects. It can be said that, "Internet celebrity" is a kind of icon which represents the typical female image in users' minds. Peirce also divided icons into three categories: imaginal icon, diagrammic icon and metaphorical icon. The image of "Internet celebrity" can be regarded as metaphorical icon.

For metaphorical icons, the semblance exists in thought. For instance, "Internet celebrities" can display their dresses and diction styles in the social platform, but behave totally different in the real world. Audiences can accept their "true" images on the network. Many women praise and imitate "Internet celebrities" because they are the metaphorical icon of ideal female images. "Internet celebrities" select their dresses carefully. After taking photos, they need to modify these pictures carefully before posting. These behaviors grasp the psychology of female audiences, and set up the intention points of symbolic interpretation.

Symbols. Symbols indicate the relationship between symbols and meanings established by social conventions. It can be said that the formation of "Internet celebrity" is a process of symbol creation; "Internet celebrity" is also a kind of symbol. Depending on the link between social and cultural significance, symbols can indicate more accurate meanings. For example, in the network culture, the rise of "Internet celebrity" is the popularity of a few beautiful female models. The public pay a lot of attention on "Internet celebrities", which make the phenomenon more popular and eventually become the symbol of some females. In such a context, "Internet celebrity" is no longer an empty word; it 
refers to women with some common characteristics. Now people often use the word "the face of Internet celebrities" to describe some women's appearance after facelift operations. It can be seen that the symbolic text of "Internet celebrity" has become a fixed symbol through social conventions.

\subsection{From "individual symbols" to "group symbols".}

The ideographic "objects" of symbols can be divided into "individual symbols" and "group symbols". According to Pierce, they are "sinsign" and "legisin". Individual symbol means the occurrence of symbol; group symbol is the attribute of concept type. The definition of "Internet celebrity" can be interpreted as an individual symbol or a group symbol from this perspective. The popularity of "Internet celebrities" is a process of transformation from a number of "individual symbols" to a "group symbol". Internet celebrities have large numbers of fans and high level media attention; they are unique characters which are different from the public. After the rise of "Internet celebrities", more and more women have joined the group of "Internet celebrity". The emergence of large-scale "Internet celebrities", together with their obvious features, makes them become a type of network culture. At that time, "Internet celebrity" is no longer a model of a beautiful shop owner on the Internet, but a group of young woman who attract great attentions.

Contemporary social culture is full of symbols; the individuality of symbols appears and vanishes rapidly. Behind the phenomenon of "Internet celebrities" is the "deep typification" of women, which makes feminists deeply detest. What makes them angrier is that women are too enthusiastic about "typification" and try their best to become typified. [2] The repetition of symbols proves the serious absence of meaning. The popular of "Internet celebrities" expose the social reality that, in today's world of free development, women begin to seek their own rights and interests in the male-dominated society, but they don't know which way to choose. Women need to correctly establish their images in society. But contemporary society is full of economic rights and more open concepts, women with more free choices are standing at the crossroad of identity. The flourishing of "Internet celebrity" offers many women, especially young women with a powerful reminder: women should be beautiful and delicate; that kind of women can be popular and even universally recognized by men. Therefore, many women choose to follow and imitate the dress and life styles of "Internet celebrity", which stimulate the popularity of so-called "top selling products" and "the dress of Internet celebrities". The diversified female images are categorized thereby. In The Consumer Society, Baudrillard said, "there is no contradiction in existence anymore, or probabilistic judgment between existence and appearance. There's only the transmission and reception of symbols, while the existence of individuals vanishes in the combination and calculation of symbols... Consumers never find their own needs." [3] Contemporary women have a lot of choices, but they cannot start from themselves and choose what they really need. They blindly follow these external symbolic stimuli, which exactly confirm the characteristics of a consumer society. The result is that, among various female images in current network culture, "Internet celebrity" become the most remarkable female image, and even the only one which attract public's attention.

\section{The Female Image of "Internet Celebrity" in Social Context}

The female image of "Internet celebrity" can win a place in today's pluralistic social culture for many reasons. As a symbolic text, the context it receives regulates the way of symbol interpretation. Analyzing from the perspective of gender differences, the centralized emergence of female image is directly related to the differences between the social statuses of men and women. In modern society, the status of women rises; but women who just liberates from gender constraint still face the problem of identity. The essence of "Internet celebrity" phenomenon is still women's compromise and ingratiation to the male-dominated society.

\subsection{The marked women.}

When two opposite terms are not symmetric, the word "markedness" can be used to refer to the term which occurs less. Markedness is common seen in cultures. In contemporary society and culture, women are no doubt the "marked term". The markedness commonly exists in social culture. In 
platforms of social network, there are many female channels which are obviously classified as "beauty" or "model". The existence of "Internet celebrity" is also a kind of marked female image.

Today's entertainment society has entered a stage of "lust for beautiful appearances". Numerous people praise women's beautiful faces and figures, which undoubtedly promotes the development of face-lifting industry in the whole world. The phenomenon is particularly prominent in Asia. The most attractive feature of Internet celebrities is their appearances. They tend to change their appearances through face-lifting surgeries. After surgeries, their faces are totally different from their original appearance, but are shockingly similar to the faces of other Internet celebrities. This kind of aesthetic pursuit has caused the so-called "face blindness" phenomenon in the public. This kind of obsession is also a social construction of women's image. Beauvior once said, "One is not born a woman, but rather becomes one. It is not the biological, psychological or economic reason that define the image of women; the whole civilization carefully processes the product. " [4] Social culture marked the beauty of women's appearance; women, as individuals in the society, have to pursue for visual beauty. Who defined this kind of beauty is exactly the point. The so-called beauty of "Internet celebrities" is in line the aesthetic orientation of men. For instance, they tend to wear sexy clothes and accessories, and grow black, long hair which is fond by most Chinese men. The rise of Internet celebrity is inseparable from male audiences' strong identification of this kind of aesthetic pursuit. The news of relationship between stars and Internet celebrities can quickly attract public attention, which indicates that excellent men like this kind of women. It is a kind of construction and processing of women in social context. The society is more concerned about male around females, rather than the characteristics of female themselves. Meanwhile, many women choose this kind of aesthetic orientation because they want to cater for men's preferences. In that environment, women's aesthetic reference is no longer their individual choice, but a compromise under social pressure.

The initial prosperity of Internet celebrity conveyed feminist color: it is not a bad choice for young women to make full use of new media platform and start up their own business. But in essence, the popularity of "Internet celebrity" relies on male identification. Women eventually falls into the trap of male chauvinism standard. The top-selling products of "Internet celebrity" and the convergence of female audience's appearance reflect the uneasiness of marked term. Popular culture is the popular pursuit of the masses; it is a universal phenomenon in the entertainment world. But the popularity of female aesthetic is not only a kind of spiritual entertainment; it involves the choice of women on their own identity.

\subsection{The choice of women in double axis.}

There are two expansion dimensions of symbol text: combination axis and aggregation axis. All the ideographic activities of symbols are inseparable from the two axes. The combination axis is about how symbols form a text; the aggregation axis is the possibility of selection of each symbol component. The combination of text is clearly expressed; the aggregation system is hidden behind. The exploration of aggregation system is the exploration of text composition.

The choice of women's image should be pluralistic. It could be represented as different aesthetic styles, or different occupations. It is a broad choice, that is, there is large range of choice behind the text. The image of Chinese women in history was always a narrow choice. The history of foot binding for one thousand years is a good illustration. There is no doubt that contemporary women who are free from the feudal patriarchal society and enjoy wider choice, or a wider axis of aggregation. The liberation of gender is accompanied by the rapid development of social environment; the emergence of symbols brings women with short time pleasure and endless confusion. People in society need to find themselves in their communications with social symbols. Human beings are social animals; they need to ensure their existence through continuous semiotic activities. In the era of symbol consumption, women in society are faced with endless choices. Kierkegaard once said, "Anxiety is the dizziness of freedom." [5] When the boundary of aggregation axis is too large to be imagined, it brings a sense of insecurity on people's identity recognition. The image of women could be pluralistic, but most women are more concerned about, which kind of female image can help them to get a stable position in society. In such a dilemma, people are more rely on existing combination relations in the 
culture. This situation makes the seemingly wide choice actually become a narrow choice. Despite the variety of choices, women are still willing to choose a typical image which is more in line with social conventions. In a macroscopic view, the sudden centralization of the broad aggregation axis creates a pin-point in social culture, attracting the attention of all people and leading countless confused women to the same direction.

\section{Conclusions}

As a multimedia symbol, "Internet celebrity" imposes increasing influence on the Internet culture and the world as a whole. As a unique female image, it affects modern women's self-identification and self-image construction to some extent. Nowadays, the image of women is no longer confined to their homes; the value of women is no longer limited in their aesthetic merits. Modern women should learn to correctly interpret different symbols and rationally make their own choices. Only in this way, can female images present the beauty of pluralism.

\section{References}

[1] C. S. Peirce, Collected Papers, Cambridge Mass: Harvard University Press, Cambridge, 1931-1985.

[2] J.V. Buren, The semiotics of gender, J. Journal of American Academy of Psychoanalysis. 20 (1992).

[3] J. Baudrillard, the Consumer Society, Nanjing University Press, Nanjing, 2007.

[4] S. Beauvoir, Le Deuxieme Sexee, Groupe Gallimard, Paris, 1949.

[5] S. K. Anxiety is Dizziness of Freedom: The Concept of Anxiety, Princeton University Press, Princeton, 1980. 